\title{
Initial investigation of the wavelength dependence of optical properties measured with a new multi-pass Aerosol Extinction Differential Optical Absorption Spectrometer (AE-DOAS)
}

\author{
R. T. Chartier ${ }^{1, *}$ and M. E. Greenslade ${ }^{1}$ \\ ${ }^{1}$ University of New Hampshire, Department of Chemistry, Durham, NH 03824, USA \\ *now at: RTI International, Research Triangle Park, NC, USA \\ Correspondence to: M. E. Greenslade (margaret.e.greenslade@unh.edu)
}

Received: 28 August 2011 - Published in Atmos. Meas. Tech. Discuss.: 12 October 2011

Revised: 14 March 2012 - Accepted: 20 March 2012 - Published: 5 April 2012

\begin{abstract}
Atmospheric aerosols directly affect climate by scattering and absorbing radiation. The magnitude of the impact is dependent upon the wavelength of light, but is often estimated near $550 \mathrm{~nm}$. When light scattering and absorption by aerosols is approximated, the wavelength dependence of the refractive index for specific components is lost. As a result, climate models would have inherent uncertainties for aerosol contributions to radiative forcing when considering the entire solar spectrum. An aerosol extinction differential optical absorption spectrometer has been developed to directly measure aerosol extinction at mid-ultraviolet to near infrared wavelengths. The instrument consists of a spectrometer coupled to a closed White-type multi-pass gas cell with an adjustable path length of up to approximately $20 \mathrm{~m}$. Laboratory measurements of various gases are compared with known absorption cross sections. Additionally, the extinction of monodisperse samples of polystyrene latex spheres are measured and compared to Mie theory generated with refractive index values from the literature to validate the new instrument. The polystyrene experiments also emphasize the ability of the new instrument to retrieve the wavelength dependent refractive index, especially in the ultraviolet wavelength regions where variability is expected. The spectrometer will be a significant advancement for determining wavelength dependent complex refractive indices in future laboratory studies as well as provide the ability to monitor ambient aerosol light extinction.
\end{abstract}

\section{Introduction}

The Earth's radiation balance is directly impacted by aerosols that can scatter and absorb radiation. Further, this balance is indirectly affected by aerosols as they can serve as cloud condensation nuclei (CCN), which can alter cloud properties and change how clouds interact with solar and terrestrial radiation. Characterizing the optical properties of aerosols in relationship to their direct effects on climate has been the focus of select studies, while many focus on experimentally determining optical properties or modeling their climate effects (Bates et al., 2006; Ge et al., 2010; Kanakidou et al., 2005; Massoli et al., 2009; Moffet and Prather, 2009). Model simulations have led to the conclusion that the radiative forcing by anthropogenic aerosols is comparable in magnitude to that of some greenhouse gases (IPCC, 2007). Despite this recent progress, some large uncertainties still remain in the understanding of aerosol optical properties, classification and loading. Decreasing specific uncertainties, such as the wavelength dependence of scattering and absorption by aerosols, can lead to improved understanding of climate change.

The wavelength dependence of aerosol optical properties, specifically the aerosol optical depth (AOD), is typically approximated in current research by the Ångström exponent, introduced by Anders Ångström (Ångström, 1929, 1930). The equation describing the wavelength dependent optical depth of particulate matter is:

$\tau_{\mathrm{a}}=\beta \lambda^{-\alpha}$

where $\tau_{\mathrm{a}}$ is the aerosol optical depth in the atmosphere, $\beta$ is the turbidity coefficient defined by Ångström at a wavelength of $1 \mu \mathrm{m}, \lambda$ is the wavelength ( $\mu \mathrm{m})$ where $\tau_{\mathrm{a}}$ is observed, and $\alpha$ is the Ångström exponent, which is equivalent to the ratio of the natural $\log$ of Eq. (1) at two different wavelengths. 
The Ångström exponent formulation has also been used to refer to the wavelength dependent absorption, extinction or scattering of particulate matter and these alternate representations will be noted in our manuscript with the addition of subscripts. However, based on the work of Mie, Ångström notes that this equation is only valid over a limited wavelength range (Ångström, 1929). In fact, Eck and co-workers showed that ambient measurements of biomass burning and urban/industrial aerosols was better fit with a second order polynomial function than the linear representation of Eq. (1) for the wavelength range from 340 to $1020 \mathrm{~nm}$ (Eck et al., 1999). This observed curvature is an indication that Eq. (1) cannot be used over this large wavelength range or the range of the solar spectrum. In contrast, observations of desert dust were consistently represented by Eq. (1). The authors attribute their mixed results to differences in the size distributions of aerosols, where the former is more likely to be accumulation mode while the latter is centered in the coarse mode (Eck et al., 1999).

The Bergstrom et al. study of aerosols in the north Atlantic (TARFOX) investigated the wavelength dependence of the absorption of black carbon particles (Bergstrom et al., 2002). In their work, they investigated size effects as implicated by Eck as well as the wavelength dependence of the refractive index (RI). Bergstrom et al. (2002) also compiled data from previous studies and in comparison with their work, indicate that the complex refractive index (CRI), where the CRI $(m)$ is given as $m=n+k i$ with $n$ being the real part and $k$ being the imaginary part, of soot ranges from (1.3 to 2.2$)+(0.8$ to 1.3$) i$ between 300-3000 nm (Bergstrom et al., 2002). The authors indicate that the single scattering albedo (SSA - the ratio of scattering efficiency to total extinction efficiency) from aerosols of black carbon mixed with non-absorbing species decreases with increasing wavelength, which contrasts with results for mineral dust aerosol SSA that increases with increasing wavelength (Bergstrom et al., 2002). A single scenario does not account for these cases.

In addition to the above, the classifications of aerosols used to broadly define their optical properties and climate impact have recently been expanded from broader categories such as black carbon, organic carbon and inorganic species to include brown carbon $(\mathrm{BrC})$ and yellow carbon (Andreae and Gelencsér, 2006; Bond and Bergstrom, 2006; Kirchstetter et al., 2004; Moosmüller et al., 2011; Yang et al., 2009). The colored organic compounds which make up these new classifications have increases in absorption, sometimes significant, with decreasing wavelength, especially into the ultraviolet (UV) wavelength region (Andreae and Gelencsér, 2006; Moosmüller et al., 2011). The wavelength dependent absorption of $\mathrm{BrC}$ leads to $\alpha_{\mathrm{abs}}>1$, but different methods of determination yield a range of results. For example, ground based optical filter methods result in $\alpha_{\text {abs }}$ from 1 to 3.5 , but solution phase results from aerosol extracts are much higher, with values between 4.7 and 16 (Bond, 2001; Bones et al., 2010; Chen and Bond, 2010; Hecobian et al., 2010; Hoffer et al., 2006; Kirchstetter et al., 2004; Marley et al., 2009; Yang et al., 2009). This discrepancy in $\alpha_{\text {abs }}$ for aerosols and their extracts needs to be reconciled. Therefore, it is important to quantify the wavelength dependence of the aerosol optical properties, especially the CRI, as systematically as possible, with preference for in situ techniques.

The optical properties of aerosols are impacted by the wavelength dependence of the CRIs of the chemical species from which they are composed. The wavelength dependence of the RI for some aerosol components is known. Techniques such as ellipsometry and vacuum ultraviolet reflectance spectroscopy can be used to obtain both the real and imaginary portion of the CRI (French et al., 2007). Once known, the values can be used in theoretical models, such as Mie calculations, to generate estimates for the aerosol optical properties. For example, the wavelength dependence of the CRI for polystyrene and polystyrene latex spheres (PSLs), where the latter are often used as a calibration tool in aerosol research, has been studied. Recently, a number of reported RI values including some dating back to the 1950s for polystyrene were employed in a comprehensive paper (Miles et al., 2010a). The wavelength range for most of the values was longer than $400 \mathrm{~nm}$, so we do not incorporate all of them in our work (Miles et al., 2010a). But we do consider that Miles et al. (2010a) mention the lower refractive indices reported by Ma et al. in comparison to other literature values and that the previous measurements were made with different forms of polystyrene, bulk or suspension (Ma et al., 2003; Miles et al., 2010a). We consider several values for the RI reported near $589 \mathrm{~nm}$ : French et al. (2007) report $1.591+0.047 i$ for PS-677 at $590 \mathrm{~nm}$, Ma et al. (2003) report 1.584 for PSLs at $590 \mathrm{~nm}$, Nikolov and Ivanov (2000) report 1.592 for thin film polystyrene at $588 \mathrm{~nm}$, while, the manufacturer, Thermo Scientific reports 1.59 for the PSLs at $589 \mathrm{~nm}$ (French et al., 2007; Ma et al., 2003; Nikolov and Ivanov, 2000). There is little variation in RI at this wavelength, leading to small differences in calculated optical properties, but the values diverge with decreasing wavelength as shown in Fig. 1. Approaching the UV $(\lambda<400 \mathrm{~nm})$, there is significant variability in the CRI values that may result from differences in the manufacturing processes for the polystyrene samples or measurement uncertainty. There are many types of polystyrene that have different physical and chemical properties such as molecular weights, densities and polarities. The variation in the CRI is matched by fluctuations in the extinction results for aerosols composed of polystyrene especially since some of the CRI changes are abrupt and significant. To our knowledge, below $\lambda=370 \mathrm{~nm}$, the RI of polystyrene has only been studied by French et al. (2007). As seen in Fig. 1 (right axis), their data show a large and dramatic increase in the imaginary portion of the CRI below $230 \mathrm{~nm}$ and from approximately 300-400 nm (French et al., 2007). Measurements at UV wavelengths are of particular importance when monitoring aerosol optical properties because this is a region of potentially dramatic change in optical properties for certain 


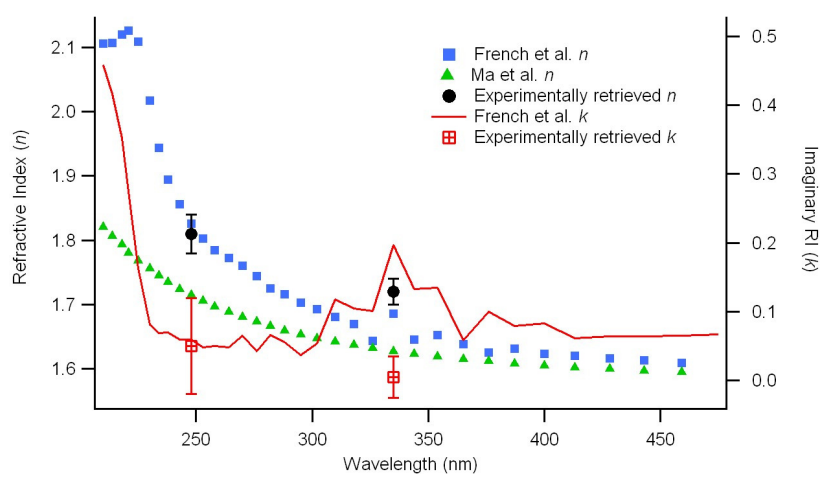

Fig. 1. The refractive index values from the literature reported and extrapolated to UV wavelengths are shown here. The literature values are used in as an input for Mie theory to allow comparison with experimental results. The left axis displays the values for the real portion of the refractive index ( $n$ ) with the French et al. (2007) values shown as blue squares and the Ma et al. (2003) values shown as green triangles. The experimentally retrieved values for $n$ are displayed as solid black circles including uncertainty. The imaginary portion of the refractive index $(k)$ is reported on the right axis where the French et al. (2007) data from the literature is shown as a connected red line and the experimentally retrieved $\mathrm{k}$ values are given as red grid boxes.

types of aerosols, especially those with some color like $\mathrm{BrC}$ (Andreae and Gelencsér, 2006; Bond and Bergstrom, 2006; Kirchstetter et al., 2004; Moosmüller et al., 2011; Yang et al., 2009). Optical properties can be used for classification and the variability may be significant at higher altitudes for climate predictions.

A variety of instruments measure aerosol optical properties, but this is often only at a single wavelength or a few select wavelengths. Some instruments have been designed to measure aerosol optical properties as a function of wavelength. For example, differential optical absorption spectroscopy (DOAS) or similar techniques have been used to directly measure aerosol extinction (the sum of scattering and absorption) (Hönninger et al., 2004; Mogili et al., 2007; Schnaiter et al., 2003, 2005; Si et al., 2010; Takashima et al., 2009; Virkkula et al., 2005). This technique uses a broadband light source to determine the differential spectra of a sample versus background. It is most commonly used to determine the concentration of trace gas species in the atmosphere, but it has also been used to measure aerosol extinction. With long, open paths, these instruments can have low detection limits for aerosol extinction (Hönninger et al., 2004; Si et al., 2010; Takashima et al., 2009). However, typical DOAS instruments with open paths can only be used to measure the optical properties of a bulk aerosol sample (Platt and Stutz, 2008) and therefore cannot be used to differentiate between aerosol type and the specific optical properties of the constituents of that aerosol sample. A limited number of laboratory instruments based on DOAS are capable of measuring aerosol extinction over the majority of the solar spectrum, some at atmospherically relevant particle concentrations. An optical extinction cell (OES) was developed to measure extinction at three wavelengths $(467,530,660 \mathrm{~nm})$, but the sample path length is $330.2 \mathrm{~cm}$, which makes this instrument sensitive enough to measure very concentrated aerosol samples (Virkkula et al., 2005). An Ocean Optics $\mathrm{UV} / \mathrm{Vis}$ spectrometer has been coupled to an environmental chamber to measure the extinction of mineral dust from 250$800 \mathrm{~nm}$, but the sample path length of $66.5 \pm 0.5 \mathrm{~cm}$ leads to a detection limit useful only for high particle concentrations (Mogili et al., 2007). A dual-beam long path extinction spectrometer (LOPES) has been used to measure aerosol extinction from $200-1100 \mathrm{~nm}$ with a $2.5 \mathrm{~nm}$ spectral resolution (Schnaiter et al., 2003, 2005). The $10 \mathrm{~m}$ LOPES instrument uses a corner cube design and is able to accurately measure extinction over the entire wavelength range with a lower detection limit of $20 \mathrm{Mm}^{-1}$, which is adequate for measuring extinction in polluted urban areas where total extinction can reach levels of upwards of $1000 \mathrm{Mm}^{-1}$ (Andreae et al., 2008; Schnaiter et al., 2005). A commercial white light aerosol spectrometer (WELAS) available from PALAS GmbH (Germany) operates from $370-780 \mathrm{~nm}$ and has been employed by Flores et al. (2009) to determine aerosol extinction and retrieve refractive indices, however, these are reported as an average from 400-800 $\mathrm{nm}$ and are not wavelength resolved (Flores et al., 2009). A cavity attenuated phase shift (CAPS) spectroscopy instrument has been tested at 445 and $632 \mathrm{~nm}$ with an effective path length of $2 \mathrm{~km}$ and is reported to have a precision of $\sim 0.2 \mathrm{Mm}^{-1}$, but is limited to a single wavelength per experiment (Massoli et al., 2010). Cavity ring down (CRD) instruments have been built with several wavelength channels or small spectral ranges, including 1550 , 1520, 1064, 683, 675, 620, 570-540, 532, 425-385, 390, $355 \mathrm{~nm}$, with excellent precision (Baynard et al., 2007; Bulatov et al., 2002; Butler et al., 2009; Dinar et al., 2008; Mellon et al., 2011; Miles et al., 2010b; Moosmüller et al., 2005; Pettersson et al., 2004; Smith and Atkinson, 2001; Spindler et al., 2007; Strawa et al., 2003, 2006).

Our aerosol extinction differential optical absorption spectrometer (AE-DOAS) is unique because it is a broadband instrument and continuously covers nearly the entire solar spectrum from 220 to $1050 \mathrm{~nm}$ with better than $0.5 \mathrm{~nm}$ resolution. In the following, we will show that the AE-DOAS has good precision in repeat measurements. Further, its wavelength calibration was investigated and confirmed using gases which absorb strongly in this range, specifically ozone and acetone. The results are compared with known absorption cross sections from the literature for wavelength agreement. The accuracy is investigated with aerosols, specifically PSLs, through comparison with a Mie theory model. The model is generated with literature values of the wavelength dependence of the RI of polystyrene and extrapolations of these values, though only one direct comparison with prior research is possible at UV wavelengths (French et al., 2007; 
Ma et al., 2003; Nikolov and Ivanov, 2000). We will show that the strong changes seen in the UV region for the imaginary portion of the CRI by French et al. (2007) were not observed in our particular polystyrene sample. By monitoring various sizes of PSLs, a closure loop is used to determining the wavelength dependent CRI for polystyrene at select wavelengths (Abo Riziq et al., 2007; Lang-Yona et al., 2009; Miles et al., 2010a). Our results further emphasize the need to monitor the wavelength dependence of aerosol optical properties.

\section{Experimental}

A bench-top AE-DOAS was custom manufactured by Cerex Monitoring Solutions, LLC (CMS UV-5000) to monitor aerosol extinction, despite the use of absorption in the historical name. This system consists of a 100 watt continuous duty xenon (Xe) lamp, fiber-optically coupled to a Whitetype multi-pass gas cell, and then to a single beam UV/Vis spectrometer as shown in Fig. 2. The White-type multiple reflection system is composed of three separate concave mirrors, each having the same radius of curvature. The distance between the mirrors is twice the focal length in order to clearly reproduce the image of the light source on the mirrors (White, 1942). The Xe lamp and coated mirrors provide spectral coverage ranging from the mid-ultraviolet to near infrared (approximately $220-1050 \mathrm{~nm}$ ) at a resolution of better than $0.5 \mathrm{~nm}$. The lamp intensity is not smooth over the entire spectral range but rather contains a large broad peak spanning the UV and visible up to approximately $750 \mathrm{~nm}$. At wavelengths between $780-880 \mathrm{~nm}$, the lamp intensity is low, and after $900 \mathrm{~nm}$ there are sharp emission peaks from the Xe lamp. This is all corrected for by routinely taking background measurements before sample measurements, but sharp features above $750 \mathrm{~nm}$ can be seen in some spectra and the instrumental detection limit at a specific wavelength is directly related to the lamp intensity at that wavelength.

The stainless steel multi-pass gas cell (left-half of Fig. 2) has outer dimensions of $73.0 \mathrm{~cm} \times 19.2 \mathrm{~cm} \times 7.5 \mathrm{~cm}$ and an internal volume of approximately 5.81. Spacers present in the bottom of the gas cell minimize the internal volume and reduce sample residence times. While these spacers may increase the likelihood of turbulence, flow rates are kept low to minimize the impact. The path length can range from 2.44 to $19.51 \mathrm{~m}$ and is adjusted by counting the number of reflections on the primary mirror. Alignment of the incident beam within the multi-pass cell is achieved by slight movements of the mirrors in conjunction with monitoring the lamp spectrum shape and intensity. A fiber optic cable transfers the light back to the spectrometer. The spectrometer consists of a grating and a 3078 element linear diode array (LDA), which is standard for UV/Vis spectroscopy. In this work, a path length of $19.51 \mathrm{~m}$ was used for all experiments unless otherwise noted.

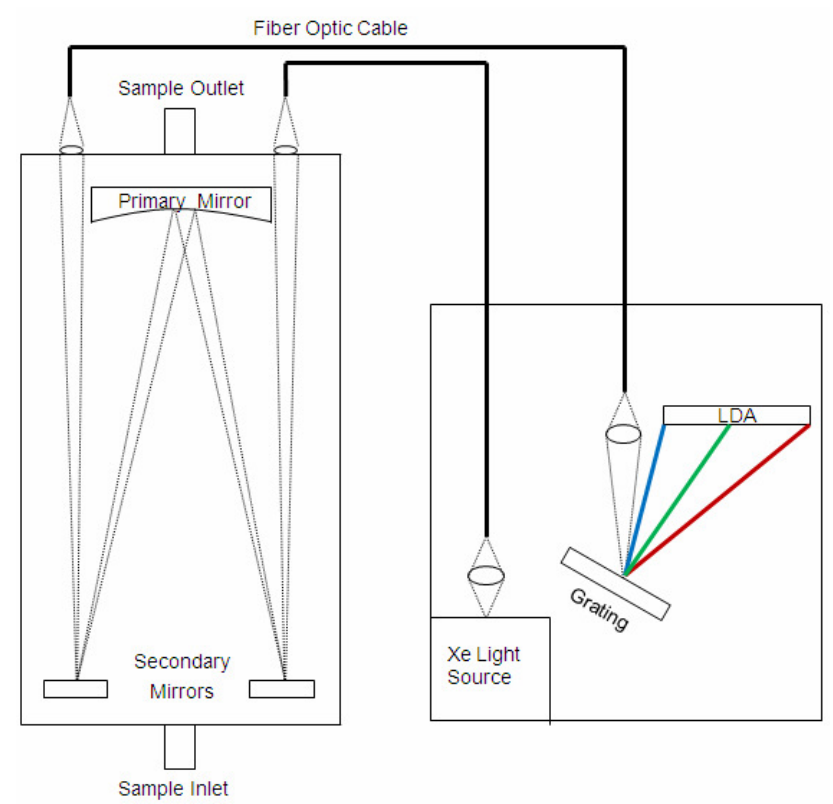

Fig. 2. A schematic of the benchtop AE-DOAS system. Light from the xenon lamp in the rack mountable spectrometer (shown on the right) is focused onto a fiber optic cable for transfer into the multipass gas cell (shown on the left). After a number of passes in the gas cell, the reflected light is focused onto a second fiber optic cable and detected by the spectrometer.

In analytical chemistry, instrumental detection limits are commonly defined as $3 \sigma$ of the baseline noise of two consecutive measurements, and a representative example of the AE-DOAS wavelength dependent detection limit is shown in Fig. 3. This detection limit was calculated using two consecutive measurements of particle free nitrogen with a path length of $19.51 \mathrm{~m}$ and an integration time of $180 \mathrm{~s}$ as is used for the laboratory based aerosol experiments in this work. The increases in detection limit seen in Fig. 2 below $235 \mathrm{~nm}$ and above $700 \mathrm{~nm}$ are due to the decreased intensity of the lamp and variable mirror reflectivity. The average detection limit of the AE-DOAS from $235-700 \mathrm{~nm}$ is $32.5 \mathrm{Mm}^{-1}$. The lower detection limit of the AE-DOAS measurement shown in Fig. 3 is $12.6 \mathrm{Mm}^{-1}$ at $366 \mathrm{~nm}$ and has been observed to be as low as $6.2 \mathrm{Mm}^{-1}$ at approximately $350 \mathrm{~nm}$ during background sampling before experiments. For comparison, the lower detection limit of the LOPES instrument is reported to be $20 \mathrm{Mm}^{-1}$ (Schnaiter et al., 2005). The detection limit of the AE-DOAS is variable, but can be calculated for any experiment by finding $3 \sigma$ of the baseline for the last two zero measurements before the sample is introduced. In addition, zeros can be compared before and after sample measurement to indicate a change in baseline, though experimental times are kept as short as possible to minimize drift. Based on the lamp spectrum and detection limit, we will primarily use the instrument in the $235-700 \mathrm{~nm}$ wavelength range. The experimental results presented in the subsequent sections focus 


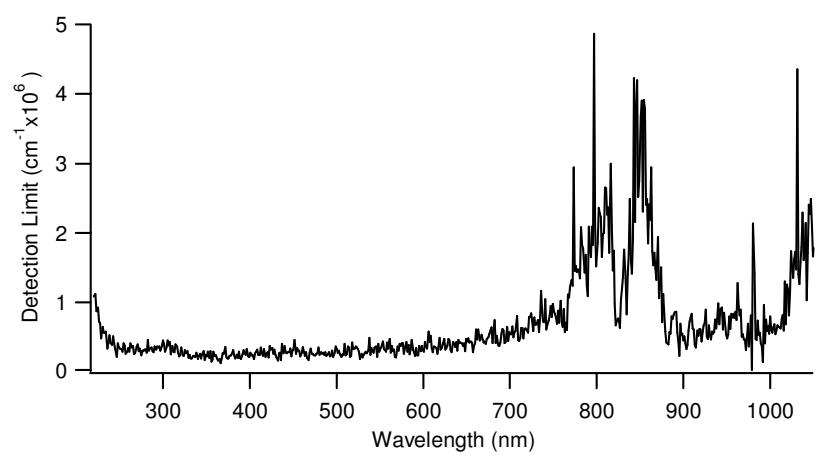

Fig. 3. The AE-DOAS detection limit is shown as a function of wavelength. This data is smoothed by averaging over five recorded wavelength values. It is clear that the detection limit is steady over the center of the solar spectrum from $235-700 \mathrm{~nm}$. At wavelengths outside this range, the detection limit increases due to low lamp intensity and is not used in our experiments.

on the precision of our measurements over a number of trials and also give an indication of the noise levels of the instrument.

Experiments were conducted with gas phase species, specifically ozone and acetone samples, as a wavelength calibration to show that the detector was properly aligned. The gas of interest is directed through the gas cell by positioning a small pump (Hargraves mini diaphragm pump, H037A-11) operating at $31 \mathrm{~min}^{-1}$ at the outlet. The ozone was produced by a spark discharge ozone generator and was monitored with a path length of $9.75 \mathrm{~m}$. For the acetone experiment, an open vessel containing liquid acetone was simply placed at the inlet to the gas cell and the vapor pressure entrained sufficient acetone into the sample flow to allow measurement.

The absorption of light by gas phase species can interfere with aerosol extinction measurements. Based on three year local maxima observed at a UNH operated field site (Thompson Farm) for 40 gas phase species and literature values for absorption cross sections, it was determined that the most significant interferences would occur in the UV and that the most important species to monitor are ozone, nitrogen dioxide, sulfur dioxide, and water (AIRMAP, 2004). As long as significant concentration changes of these gases are not encountered during the course of an ambient experiment, interferences can be accounted for by measuring filtered, aerosol free ambient air as a background. We do not use filters in the experiments presented here, but future experiments will include temperature and pressure monitoring in the gas cell to allow corrections for Rayleigh scattering. For the gas phase experiments presented here, laboratory air was used as a background and compared to laboratory air enhanced in the species of interest. In the laboratory aerosol experiments, particle free nitrogen is used as a background and for aerosol generation to minimize gas phase interferences.
Polystyrene latex spheres have a small $(\leq 5 \%)$ coefficient of variation in diameter and are often used as a proxy for monodisperse spherical aerosols. PSLs interact with light as predicted by Mie theory, and therefore make a good calibration standard for aerosol measurement techniques (Baynard et al., 2007; Cai et al., 2006; Galli et al., 2001; Lang-Yona et al., 2010; Liu et al., 2010; Miles et al., 2010a). All PSL solutions in this work were made fresh and mixed in test tubes by diluting 15 drops of $10 \%$ w/w PSL solution (Duke Scientific Corporation, now part of Thermo Scientific) in $20 \mathrm{ml}$ deionized water (J. T. Baker, HPLC Water). To measure a monodisperse PSL aerosol sample the setup in Fig. 4 was used. In detail, the aerosol sample was atomized then dried to a relative humidity of $<3 \%$ by flowing over molecular sieves housed in a diffusion dryer. The dried aerosol sample was size selected at the diameter of the PSLs by a differential mobility analyzer (DMA - TSI model 3080L). The monodisperse PSL sample then enters the AE-DOAS where continuous extinction measurements are made as the sample flows through the gas cell. Upon exiting the gas cell, the aerosol sample enters the condensation particle counter (CPC - TSI model 3775). The uncertainty of the counted particle concentrations is $\pm 10 \%$.

Particle concentration varies as a function of time during an experiment. The highest AE-DOAS extinction signal for an experiment is assumed to correspond to the maximum aerosol concentration for the experimental trial. A time offset is defined as the difference between the start time of the AE-DOAS measurement with the highest extinction and the time the maximum concentration was measured by the CPC and is due to particle build up in the volume of the gas cell and the travel time between the gas cell and the CPC. For all PSL measurements discussed in this work, the time offset from the AE-DOAS measurement to the aerosol concentration measurement was between $8.5-10.5 \mathrm{~min}$. In a typical 45 min experiment, the particle concentration rises quickly to a maximum in the first $10 \mathrm{~min}$, decreases slightly to a steady state and remains within the CPC error for $25 \mathrm{~min}$ and decreases within $10 \mathrm{~min}$ after the atomizer pump is turned off. The steady state particle concentration window is used for the relatively short optical measurements. During specific optical measurement of 120 or $180 \mathrm{~s}$ integration, an equivalent average was used for particle counting results; in a representative experiment, the standard deviation $(1 \sigma)$ on the particle concentration during the steady state window was $4 \%$.

The flow rate through the system is kept low during experiments $\left(0.31 \mathrm{~min}^{-1}\right)$ yielding a low Reynolds number indicative of laminar flow. The mirrors are not protected from contamination by a purge flow; however, sensitivity experiments following heavy use conducted before and after mirror cleaning and realignment show results within experimental uncertainties. In addition, during the particle free background for aerosol sampling, particle counts reached zero as is necessary to avoid spurious results and thus give no indication of re-entrainment of surface bound particles. 


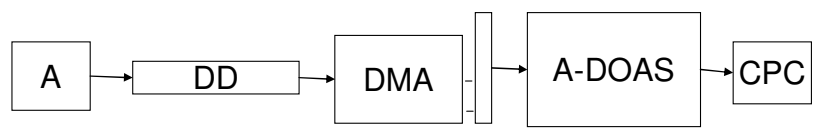

Fig. 4. A flow diagram of experimental setup used to measure the optical properties of a monodisperse PSL sample with the AEDOAS. $\mathrm{A}=$ atomizer, $\mathrm{DD}=$ diffusion dryer, $\mathrm{DMA}=$ differential mobility analyzer, AE-DOAS = aerosol extinction differential optical absorption spectrometer, which is shown in detail in Fig. 2, and $\mathrm{CPC}=$ condensation particle counter. Additional instrument details are given in the experimental section.

Mie calculations using three different sets of refractive indices for polystyrene were performed using Fortran and MatLab programs (Bond Research Group, 2008) based on that of Bohren and Huffman (Bohren and Huffman, 1983; Mätzler, 2002). The calculated Mie extinction cross sections based on different RI values from the literature were compared with the experimental results. Aerosol extinction cross section is analogous to the gas phase molecular absorption cross section and is calculated as the raw extinction value $\left(\mathrm{cm}^{-1}\right)$ divided by the particle number concentration (particles $\mathrm{cm}^{-3}$ ) to yield units of $\mathrm{cm}^{2}$ particle ${ }^{-1}$. Alternatively, the value of $Q_{\text {ext }}$, which is the dimensionless efficiency of extinction calculated by dividing the extinction cross section by the geometric cross section of the aerosols, can be plotted versus size parameter $(\chi)$, which is defined as $\pi d / \lambda$, where the diameter $(d)$ is varied. The latter method is reported for a single $\lambda$ but can be duplicated at many different wavelengths and has been used previously to validate CRD instruments (Baynard et al., 2007; Miles et al., 2010a). It can also be used to retrieve the CRI a specific wavelength by fitting the data using a closure loop (Abo Riziq et al., 2007; Dinar et al., 2008; Erlick et al., 2011; Flores et al., 2009; Freedman et al., 2009; Kim et al., 2010; Lack et al., 2006; Lang-Yona et al., 2009; Mack et al., 2010; Miles et al., 2010a, b).

\section{Results}

Ozone has broad absorption bands throughout the UV/Vis spectrum and high concentrations can be readily observed by the AE-DOAS (Voigt et al., 2001). The absorption of ozone measured by the AE-DOAS is shown in Fig. 5. This is the Hartley band which spans from approximately 200 $300 \mathrm{~nm}$ with an intense absorption peak centered at $255 \mathrm{~nm}$. Figure 5 also compares our results with literature (Bogumil et al., 2003). It was necessary to adjust the AE-DOAS spectrum by adding $1 \mathrm{~nm}$ to the result to achieve excellent agreement with the fine structure in the literature spectrum. The literature absorption cross section was used to determine that approximately $650 \mathrm{ppbv}$ of ozone was present during the measurements.

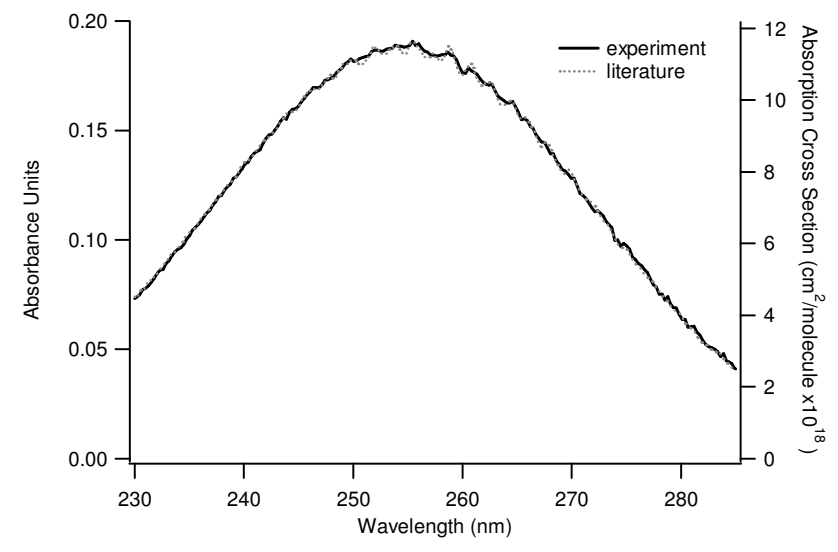

Fig. 5. The UV absorption spectrum of the Hartley band of ozone measured with an AE-DOAS path length of $9.75 \mathrm{~m}$ is shown as a solid black line. This is compared to the dotted grey line showing the absorption cross section spectrum of ozone (shown on the right y-axis) (Bogumil et al., 2003). A wavelength adjustment equivalent to adding one nanometer to the experimental spectrum is required to match the fine spectral structure seen in the literature spectrum.

Initially, acetone was identified in laboratory air as a gas phase interference near $\lambda=275 \mathrm{~nm}$ due to changing signal in background measurements. Subsequent laboratory experiments described above yielded the spectrum in Fig. 6. By comparing with literature results for acetone absorption (Meyrahn et al., 1986), also seen in Fig. 6, the interfering species was confirmed. No adjustment was required for the wavelength in this case and the alignment of the spectrometer and the linear diode array is confirmed with the standard path length. The acetone concentration during the experiment shown in Fig. 6 was determined to be 190 ppmv. Acetone is commonly used in the building and its concentration will change so the background must be monitored during ambient experiments.

An experimentally obtained wavelength dependent spectrum of the extinction cross section for $300 \mathrm{~nm}$ diameter PSLs is shown in Fig. 7. On the wavelength axis, each closed black circle shown is the smoothed average across ten raw experimental data points. Intensity of the extinction cross section is displayed as an average of eleven spectral retrievals completed on three different days, where the error bars represent one standard deviation of the mean. The error bars show the measurement precision. The accuracy of the extinction cross section measurements is governed largely by the CPC counting efficiency (Miles et al., 2010a). The accuracy of our extinction cross section results is confirmed by agreement with a Mie theory model near $590 \mathrm{~nm}$ where the RI of PSLs has been extensively studied and minimal absorption is reported. Additional experiments were performed at other path lengths and yielded similar results, though only the longest path length results are shown here for consistency. Each size of PSL has a unique aerosol extinction cross 


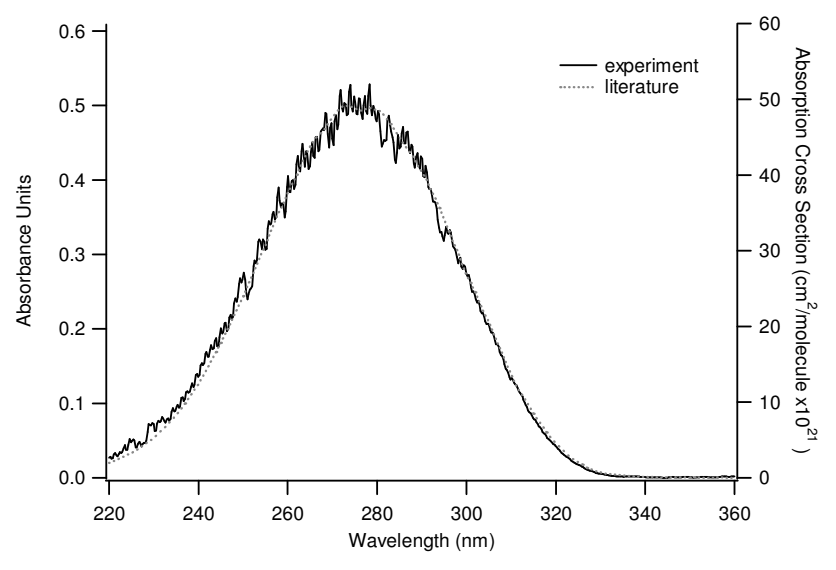

Fig. 6. The UV absorption spectrum obtained with the AE-DOAS of acetone with a 5-point boxcar average is shown as a solid black line. This is compared with the dotted grey line showing the absorption cross section spectrum of gas phase acetone (shown on the right y-axis) (Meyrahn et al., 1986).

section spectrum as a function of wavelength due to size effects. We do not show those other spectrum here but instead focus on comparisons with Mie theory while compiling those results in later figures.

Mie theory calculations are completed with RI values from the literature. The first calculation is generated using the RI of PSLs given by the manufacturer, Thermo Scientific, as 1.59 at $589 \mathrm{~nm}$ and using this value at all wavelengths (Thermo Fisher Scientific, 2012). This does not give an indication of the wavelength dependence for our experiments but rather is an approximation similar to assumptions made in some climate modeling studies. The manufacturer does discuss the wavelength dependence to the RI of the PSL in a technical document (Thermo Fisher Scientific, 2009), but references previously published data (Boundy and Boyer, 1952; Ma et al., 2003). The second set of RI data is wavelength dependent and was derived from experimental data fit to determine the reported dispersion coefficients of Cauchy's equation (Ma et al., 2003; Nikolov and Ivanov, 2000). The results of Nikolov and Ivanov (2000) are similar to Ma et al. (2003), but the former do not report index of refraction values below $436 \mathrm{~nm}$; the Ma et al. (2003) data is reported for wavelengths greater than $370 \mathrm{~nm}$, and we use their data to $370 \mathrm{~nm}$ and further extrapolate into the UV. For both the first and second calculations, the imaginary portion of the CRI $(k)$ is set at the negligible value of zero, though other low values could have been selected. The third set was determined experimentally and is reported as RI values from $207-1033 \mathrm{~nm}$ (French et al., 2007). The two sets of wavelength dependent RIs we use in our calculations differ somewhat in the real portion of the CRI $(n)$, while only French et al. (2007) data includes a non-negligible imaginary portion of the CRI $(k)$.

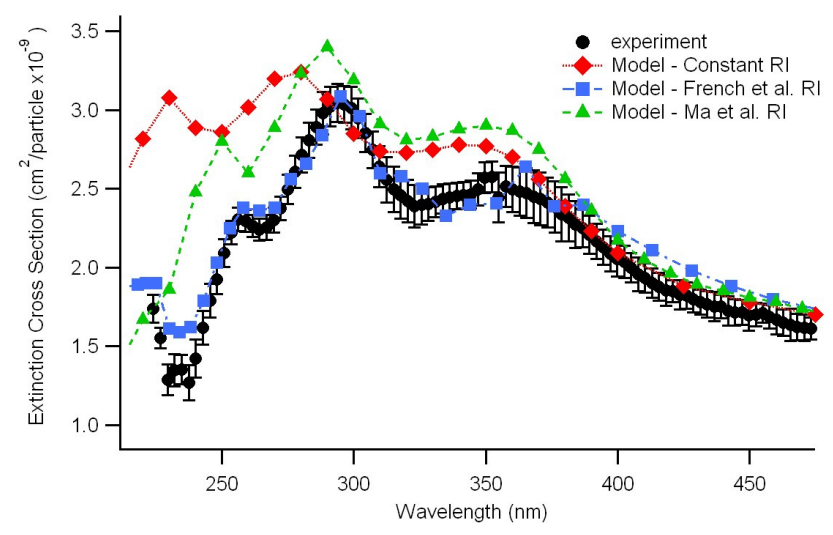

Fig. 7. The extinction cross section spectrum measured by the AEDOAS for $300 \mathrm{~nm}$ PSL is shown as solid black circles. The experimental error bars represent $1 \sigma$ of the mean. Mie theory calculations are performed with various values for the RI. The result based on the constant manufacturer's reported RI is shown as solid red diamonds, the RI derived from Ma et al. (2003) based on the Cauchy coefficients is shown as solid green triangles and the French et al. (2007) experimentally determined CRI is solid blue squares. The experiment and calculations show improved convergence at wavelengths greater than $475 \mathrm{~nm}$ and are therefore not shown.

Mie calculations performed using RI generated from the reported Cauchy coefficients are shown in Fig. 7 as filled triangles (Ma et al., 2003), while calculations using the CRI reported are shown as filled squares (French et al., 2007). The Mie calculation using the constant RI reported by the manufacturer (Thermo Fisher Scientific, 2012) are displayed as filled diamonds in Fig. 7. There is clearly a difference between the two wavelength dependent theoretical results, though the general shape of the spectra agree with a few minor issues. The theoretical calculation using the constant manufacturer's RI has a spectral shape which does not match as well as the spectra from the wavelength dependant RI. Specifically, the intensity is decreasing in the UV for our experimental spectrum, but there is a peak seen with the constant RI model. Also, with the constant manufacturer's RI, there is a blue shift of each of the peaks in comparison to the experimental AE-DOAS spectrum. For the other two theoretical results, it is clear that the RI values mainly extrapolated from Cauchy coefficients reported by Ma et al. (2003) overestimates the extinction cross sections from $220-400 \mathrm{~nm}$. The intensity of the extinction cross section model based on the French et al. (2007) complex RI most closely matches the AE-DOAS spectrum.

Since the aerosol extinction cross section spectra are unique for each PSL size, we compile this data. A representation of the size dependent aerosol extinction is reported in Fig. 8 as $Q_{\text {ext }}$ versus size parameter at a wavelength of $248 \mathrm{~nm}$. It is especially important to investigation the UV region because few experimental or theoretical results are available for these wavelengths. The 


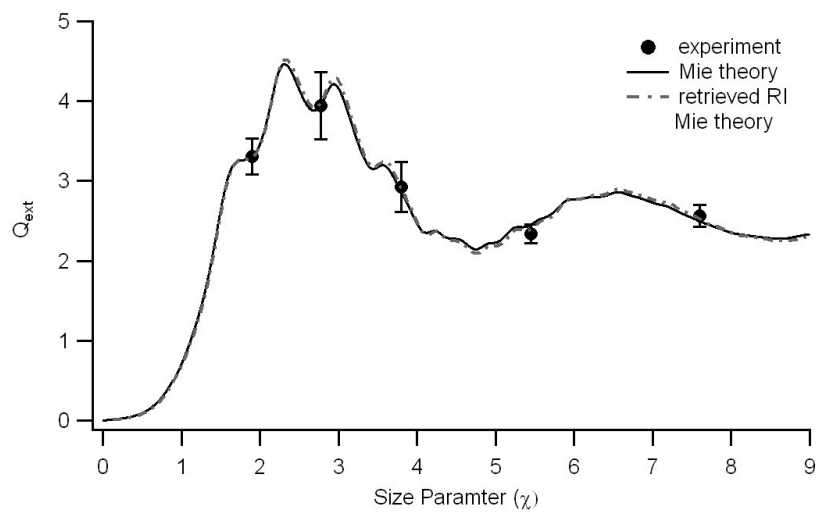

Fig. 8. The experimentally measured $Q_{\text {ext }}$ versus size parameter for PSL at a wavelength of $248 \mathrm{~nm}$ are shown as solid black circles. The black line is the Mie theory calculation performed with a CRI from French et al. (2007) $(m=1.826+0.059 i$ at $\lambda=248 \mathrm{~nm})$. The grey dot-dash line is the Mie theory calculation for the CRI retrieved from the experimental data $(m=1.81+0.05 i)$. The experimental extinction efficiency is reported for PSL diameters of $150 \mathrm{~nm}, 220 \mathrm{~nm}, 300 \mathrm{~nm}, 430 \mathrm{~nm}$, and $600 \mathrm{~nm}$ (from left to right) and the reported error bars are $1 \sigma$ for repeat measurements.

experimental measurements are depicted as closed circles and the error bars are one standard deviation of the mean for multiple measurements. The solid black line in Fig. 8 is the Mie theory calculation using the French et al. (2007) CRI, $m=1.826+0.059 i$, reported at a wavelength of $248 \mathrm{~nm}$ (French et al., 2007). The agreement is excellent as the experimental data overlaps with the Mie theory model in all cases.

Good agreement between experiment and theory is obtained at $248 \mathrm{~nm}$, however, this agreement varies at other wavelengths. Aerosol $Q_{\text {ext }}$ versus size parameter for a wavelength of $335 \mathrm{~nm}$ is shown in Fig. 9, with open circles representing the experimental data. The solid black line in Fig. 9 is the same theoretical calculation as in Fig. 8, but using the CRI of $m=1.686+0.197 i$ reported at a wavelength of $335 \mathrm{~nm}$ (French et al., 2007). A dotted light grey line is added to Fig. 9 and is a Mie theory calculation using the real portion of the French et al. wavelength dependent CRI but with the imaginary portion of the CRI set to zero. This variation improves the agreement between theory and experiment.

In addition to comparing the experimental results with several Mie theory simulations, we have retrieved the CRI at the wavelengths studied in detail $(\lambda=248$ and $335 \mathrm{~nm})$ using methods previously described in the literature (Abo Riziq et al., 2007; Dinar et al., 2008; Erlick et al., 2011; Flores et al., 2009; Freedman et al., 2009; Kim et al., 2010; Lack et al., 2006; Lang-Yona et al., 2009; Mack et al., 2010; Miles et al., 2010a, b). For this work, we have used an interface from J. Michel Flores to retrieve the CRI using the data in Figs. 8 and 9. At wavelengths of $248 \mathrm{~nm}$ and $335 \mathrm{~nm}$, PSLs are found to have a CRI of $m=1.81( \pm 0.03)+0.05( \pm 0.07) i$

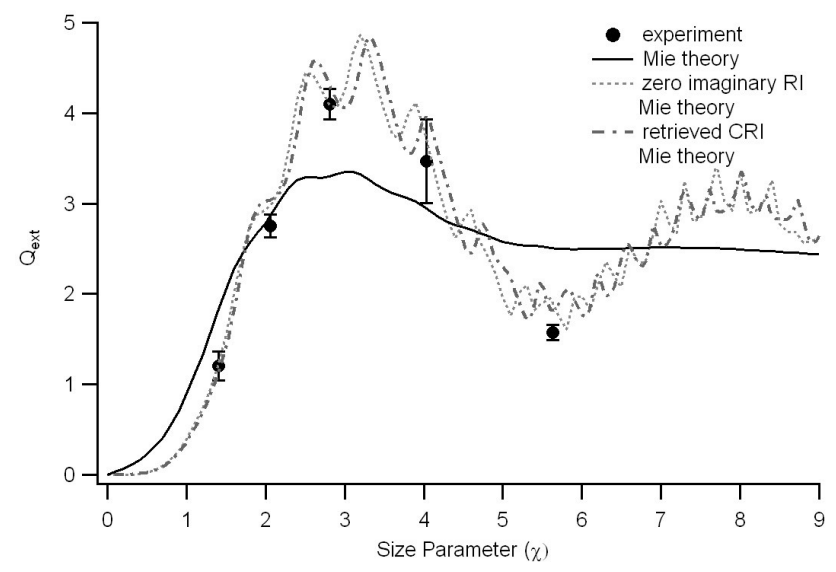

Fig. 9. At a wavelength of $335 \mathrm{~nm}$, the $Q_{\text {ext }}$ measured by the AE-DOAS (solid black circles) does not match the $Q_{\text {ext }}$ predicted by Mie theory generated with the French et al. (2007) CRI $(m=1.686+0.197 i)$ shown as the black line. The Mie theory generated when the imaginary portion of this CRI is reduced to zero is shown in the light gray dotted line. The grey dot-dash line is the Mie theory calculation for the CRI retrieved from the experimental data $(m=1.72+0.005 i)$. Errors bars are $1 \sigma$ on repeat experimental measurements.

and $1.72( \pm 0.02)+0.005( \pm 0.03) i$, respectively. These results are shown with the literature RI values for comparison in Fig. 1. Mie theory curves from the retrieved RI are also shown on Figs. 8 and 9 as grey dot-dash lines. The curves are similar to those based on the French et al. data, though improvements in the fit are visible for the $\lambda=335 \mathrm{~nm}$ case.

\section{Discussion}

The AE-DOAS spectrum of ozone shown in Fig. 5 was taken at concentrations that are greater than most polluted conditions. This high concentration could have led to minor broadening and the need for the $1 \mathrm{~nm}$ wavelength offset. Alternatively, it is possible that the alignment to the spectrometer was imperfect during this sampling with a path length of $9.75 \mathrm{~m}$, and this misalignment may have led to the observed small shift in wavelength. This problem will not contribute to issues in our aerosol measurements because they are completed with a longer path length and further the aerosol extinction is broad so small shifts in the wavelength calibration would not be significant. It should also be noted that this relatively short path length means that ambient measurements using longer path lengths may contain interferences from lower ozone concentrations. As pointed out previously, this can be overcome during measurements of ambient aerosol extinction by frequently monitoring the background gas intensity using particle free air at regular intervals. Alternatively, if the concentration is expected to change rapidly on the measurement time scale, then the ozone concentration could be monitored directly and the spectrum corrected 
using well know absorption coefficients for ozone. In order to better confirm the alignment of the system at the standard configuration with a path length of $19.51 \mathrm{~m}$, acetone was monitored. The agreement between the literature and experimental spectra in Fig. 6 is excellent. No wavelength offset is applied here and none was used for the remainder of the experiments.

In Fig. 7, it is clear that Mie theory generated by the Cauchy derived RI and the constant manufacturer's RI specified at $589 \mathrm{~nm}$ differs from the experimental spectrum of $300 \mathrm{~nm}$ PSL at wavelengths into the UV (Ma et al., 2003). The agreement between the spectrum of $300 \mathrm{~nm}$ PSL and the Mie theory calculations made using the French et al. (2007) wavelength dependent CRI provides the best agreement between our results and the three theoretical spectra (French et al., 2007). Using this model represented by filled squares that includes the imaginary part of the CRI, the agreement is especially improved at wavelengths less than $300 \mathrm{~nm}$ in the UV region of the spectrum. At wavelengths less than $370 \mathrm{~nm}$, the Ma et al. (2003) data was not provided but rather has been extrapolated and this may have lead to the disagreement observed in Fig. 7. On the other hand, all of the theoretical $300 \mathrm{~nm}$ PSL extinction cross section spectra appear to be slightly enhanced over the experimentally determined values at wavelengths greater than $400 \mathrm{~nm}$, suggesting that more light is reaching the AE-DOAS detector than is predicted by Mie theory. This over prediction is nearly resolved at wavelengths longer than $475 \mathrm{~nm}$, where any remaining disagreement may result from enhanced forward scattering at longer wavelengths.

Closer examination of Fig. 7 reveals that even the good agreement achieved with the Mie theory calculations made using the French et al. (2007) wavelength dependent CRI has spectral regions with greater deviations. For example, the Mie theory calculations predicted higher extinction cross sections from $230-240 \mathrm{~nm}$ than were measured experimentally. Differences between the theory and measured extinction cross section spectra in the wavelength range of approximately $300-370 \mathrm{~nm}$ can also be seen, though these are mostly within the error of the measurements. The agreement can be investigated in more detail by examining the value of $Q_{\text {ext }}$ as a function of size parameter at specific wavelengths.

Figure 8 depicts the experimental and Mie theory calculated extinction efficiencies for various size PSLs at a wavelength of $248 \mathrm{~nm}$. A wavelength of $248 \mathrm{~nm}$ was chosen for this calculation because Mie theory calculations appear to correlate well with the extinction measurements for $300 \mathrm{~nm}$ diameter PSL and for various other sizes. Further, the lamp is stable and the detection limit is low at a wavelength of $248 \mathrm{~nm}$. This type of depiction of extinction efficiency displays broad maxima and minima called interference structure which is due to destructive and constructive interference, respectively, between rays of scattered light. In addition, there are often smaller sharp peaks which are referred to as ripple structure. The ripple structure is smoothed when broad size distributions are monitored, aerosols absorb light, or if there is dispersion in wavelength at the light source. For these reasons, minimal ripple structure is expected. The experimental results follow the interference structure calculated for $Q_{\text {ext }}$, specifically the theoretical trace is within the $1 \sigma$ error bars at all measured sizes. The experimental results even follow the small amount ripple structure present in Fig. 8 as can be seen at the $220 \mathrm{~nm}$ diameter PSL (shown at a size parameter of nearly 3 ).

The extinction efficiency for various size PSLs at a wavelength of $335 \mathrm{~nm}$ is shown in Fig. 9. Experimental measurements at this wavelength deviate from theory in Fig. 7 and for other sizes studied; as such, the experimental and theoretical extinction efficiencies at $\lambda=335 \mathrm{~nm}$ were not expected to coincide. The disagreement is clear in Fig. 9, with strongest variability at size parameters greater than 2.5 . Careful comparison of the CRI values used for both extinction efficiency cases, highlight that the imaginary portion of the CRI is nearly four times greater at $335 \mathrm{~nm}(k=0.197)$ than $248 \mathrm{~nm}$ $(k=0.059)$ (French et al., 2007). The increase in the imaginary portion of the CRI leads to a smoothing of the interference structure indicative of an absorbing species. We would have expected $k$ to increase with decreasing wavelength, but French at al. (2007) observed an interim peak in the imaginary RI near a wavelength of $335 \mathrm{~nm}$ (French et al., 2007). In order to investigate this more closely, theoretical calculations were performed with the imaginary portion of the CRI set to zero while keeping the real portion consistent with the French et al. (2007) value. This treatment is more in line with the imaginary part of the CRI from French et al. (2007) at wavelengths greater than $413 \mathrm{~nm}$ where the value is consistently less than $0.069 i$ (French et al., 2007). The resulting trace is shown as a dotted light grey line in Fig. 9. The increased agreement with the new model is remarkable, confirming that a modest change in the imaginary portion of the CRI can lead to significant changes in the extinction efficiency at some size parameters. Our experimental results suggests that the Duke Scientific PSLs samples do not absorb light at this wavelength as readily as the thin film polystyrene samples measured by French and co-workers (French et al., 2007).

The agreement between the experiment and theory depends on the value of the CRI used in the calculations. By observing the deviations in Figs. 7, 8 and 9, it is clear that even the best CRI determined with careful experimental technique does not match our results at some wavelengths (French et al., 2007). The most probable explanation for this is variability in polystyrene samples. Some differences in the optical properties of various polystyrene samples are expected, as the manufacturing process controls these. French et al. (2007) measured two different thin film polystyrene samples in their work, and the resulting complex refractive indices were unique to each sample (French et al., 2007). Our calculations use their PS-677 sample results which has better agreement with the RI of the PSLs as reported by the 
manufacturer at $589 \mathrm{~nm}$ (French et al., 2007). Differences could arise because our PSLs are spherical, not thin films that can be subjected to different measurement techniques, and also the PSL samples contain a proprietary surfactant in the solution to reduce agglomeration, which could alter the CRI of the aerosolized PSLs. Therefore, it is not unexpected that the complex refractive indices reported for the thin film sample do not completely reproduce the extinction spectrum of the PSLs used in this work (French et al., 2007). However, these wavelength dependent complex refractive indices provide good agreement and they should continue to be used, but with some caution in the UV wavelength regions. Valid CRI representations are available other wavelength regions.

Several research groups are currently using the CRI as a floating parameter and fitting Mie theory calculations to experimental results (Abo Riziq et al., 2007; Dinar et al., 2008; Erlick et al., 2011; Flores et al., 2009; Freedman et al., 2009; Kim et al., 2010; Lack et al., 2006; Lang-Yona et al., 2009; Mack et al., 2010; Miles et al., 2010a, b; Spindler et al., 2007). This is shown to be successful even when the absorption parameter is not reported in conjunction with the extinction (or scattering) parameter (Lack et al., 2006; Mack et al., 2010). Our retrieved CRI are similar to those derived from the literature. At a wavelength of $248 \mathrm{~nm}$, the retrieved CRI including its error is equivalent to the French et al. (2007) data and little difference is observed in the Mie theory results in Fig. 8. For $\lambda=335 \mathrm{~nm}$, the retrieved CRI captures the interference and ripple features of the spectrum by improving agreement near a size parameter of 5.5, while not significantly decreasing agreement at other size parameters as seen in Fig. 9. Overall the retrieved CRI results are similar to those from the literature (French et al., 2007; Ma et al., 2003).

In conclusion, we have displayed the capabilities of a new instrument for monitoring aerosol extinction. The AE-DOAS is shown to be accurate and precise through experiments of gas phase species and polystyrene latex spheres. Further, this work clearly displays the importance of having correct CRI values at all wavelengths. Figure 7 demonstrates the variability between our results and the three different literature motivated models. Here, the three similar models emphasize that small changes in the overall value of the CRI can lead to changes in shape and intensity in the extinction cross section spectrum as a function of wavelength. Further, the effect of modest changes in the imaginary portion of the CRI at UV wavelengths as modeled in Fig. 9 can have a significant impact on the representation of extinction efficiency. The CRI of aerosol components is used as an input for climate models and it is important to consider the wavelength dependence of the values used. The importance of the UV wavelengths is due to rapid intensity changes in solar irradiance and new classification of aerosols such as $\mathrm{BrC}$ and yellow carbon that have changing CRI in this wavelength region. As a result, any uncertainties in the wavelength dependent CRI may be magnified in climate models.
In future work, we will perform a detailed analysis of our data for PSL through a minimization routine to retrieve the CRI from extinction efficiency representations at additional wavelengths, especially in the UV range where little data currently exists. We will also be studying a variety of samples in the laboratory and preparing the AE-DOAS for ambient measurements, where the latter will include investigating increased flow rates through the system to reduce the duty cycle for obtaining data and adding pressure and temperature monitors to allow Rayleigh scattering corrections. In addition, we will consider substituting the current Xe arc lamp for high power light emitting diodes (LEDs) that are beginning to be used in spectroscopic equipment for increased stability and sensitivity or moving to a broad band cavity enhanced system.

Acknowledgements. We gratefully acknowledge the contribution of J. Michel Flores to this work as he supplied the user friendly interface for retrieving refractive indices. We wish to thank Roger H. French for providing us with the numerical values used to generate the figures in his 2007 paper. We also thank three anonymous reviewers for their thoughtful and insightful comments which helped us to improve this manuscript. This work was funded by the University of New Hampshire, College of Engineering and Physical Sciences. RTC acknowledges funding from the UNH Chemistry Department and Graduate School. MEG completed much of the writing of this manuscript during the 2010 GAIN writing retreat funded by ADVANCE Grant, NSF-0620101 and ADVANCE Grant, NSF-0620087.

Edited by: P. K. Bhartia

\section{References}

Ångström, A.: On the atmospheric transmission of sun radiation and on dust in the air, Geogr. Ann. A., 11, 156-166, 1929.

Ångström, A.: On the atmospheric transmission of sun radiaiton. II., Geogr. Ann. A., 12, 130-159, 1930.

Abo Riziq, A., Erlick, C., Dinar, E., and Rudich, Y.: Optical properties of absorbing and non-absorbing aerosols retrieved by cavity ring down (CRD) spectroscopy, Atmos. Chem. Phys., 7, 15231536, doi:10.5194/acp-7-1523-2007, 2007.

AIRMAP: available at: http://airmap.unh.edu/ (last access: 29 September 2011), 2004.

Andreae, M. O. and Gelencsér, A.: Black carbon or brown carbon? The nature of light-absorbing carbonaceous aerosols, Atmos. Chem. Phys., 6, 3131-3148, doi:10.5194/acp-6-3131-2006, 2006.

Andreae, M. O., Schmid, O., Yang, H., Chand, D., Yu, J. Z., Zeng, L. M., and Zhang, Y. H.: Optical properties and chemical composition of the atmospheric aerosol in urban Guangzhou, China, Atmos. Environ., 42, 6335-6350, 2008.

Bates, T. S., Anderson, T. L., Baynard, T., Bond, T., Boucher, O., Carmichael, G., Clarke, A., Erlick, C., Guo, H., Horowitz, L., Howell, S., Kulkarni, S., Maring, H., McComiskey, A., Middlebrook, A., Noone, K., O’Dowd, C. D., Ogren, J., Penner, J., Quinn, P. K., Ravishankara, A. R., Savoie, D. L., Schwartz, S. E., Shinozuka, Y., Tang, Y., Weber, R. J., and Wu, Y.: Aerosol direct 
radiative effects over the northwest Atlantic, northwest Pacific, and North Indian Oceans: estimates based on in-situ chemical and optical measurements and chemical transport modeling, Atmos. Chem. Phys., 6, 1657-1732, doi:10.5194/acp-6-1657-2006, 2006.

Baynard, T., Lovejoy, E. R., Pettersson, A., Brown, S. S., Lack, D., Osthoff, H., Massoli, P., Ciciora, S., Dube, W. P., and Ravishankara, A. R.: Design and application of a pulsed cavity ringdown aerosol extinction spectrometer for field measurements, Aerosol Sci. Tech., 41, 447-462, 2007.

Bergstrom, R. W., Russell, P. B., and Hignett, P.: Wavelength dependence of the absorption of black carbon particles: Predictions and results from the TARFOX experiment and implications for the aerosol single scattering albedo, J. Atmos. Sci., 59, 567-577, 2002.

Bogumil, K., Orphal, J., Homann, T., Voigt, S., Spietz, P., Fleischmann, O. C., Vogel, A., Hartmann, M., Kromminga, H., Bovensmann, H., Frerick, J., and Burrows, J. P.: Measurements of molecular absorption spectra with the SCIAMACHY preflight model: instrument characterization and reference data for atmospheric remote-sensing in the $230-2380 \mathrm{~nm}$ region, J. Photoch. Photobio. A, 157, 167-184, 2003.

Bohren, C. F. and Huffman, D. K.: Absorption and Scattering of Light by Small Particles, Wiley, New York, 126-129, 475-482, 1983.

Bond, T. C.: Spectral dependence of visible light absorption by carbonaceous particles emitted from coal combustion, Geophys. Res. Lett., 28, 4075-4078, 2001.

Bond, T. C. and Bergstrom, R. W.: Light absorption by carbonaceous particles: An investigative review, Aerosol Sci. Tech., 40, 27-67, 2006.

Bond Research Group: Aerosol characterization: Mie calculations, available at: http://hiwater.org/Mie_calcs.html (last access: 29 September 2011), 2008.

Bones, D. L., Henricksen, D. K., Mang, S. A., Gonsior, M., Bateman, A. P., Nguyen, T. B., Cooper, W. J., and Nizkorodov, S. A.: Appearance of strong absorbers and fluorophores in limonene$\mathrm{O}_{3}$ secondary organic aerosol due to $\mathrm{NH}_{4}^{+}$-mediated chemical aging over long time scales, J. Geophys. Res.-Atmos., 115, D05203, doi:10.1029/2009JD012864, 2010.

Boundy, R. H. and Boyer, R. F. (Eds.): Styrene, Its Polymers, Copolymers and Derivatives, Reinhold Publishing Corp., NY, 523-525, 1952.

Bulatov, V., Fisher, M., and Schechter, I.: Aerosol analysis by cavity-ring-down laser spectroscopy, Anal. Chim. Acta, 466, 19, 2002.

Butler, T. J. A., Mellon, D., Kim, J., Litman, J., and Orr-Ewing, A. J.: Optical-Feedback Cavity Ring-Down Spectroscopy Measurements of Extinction by Aerosol Particles, J. Phys. Chem. A, 113, 3963-3972, 2009.

Cai, Y., Zelenyuk, A., and Imre, D.: A high resolution study of the effect of morphology on the mass spectra of single PSL particles with Na-containing layers and nodules, Aerosol Sci. Tech., 40, 1111-1122, 2006.

Chen, Y. and Bond, T. C.: Light absorption by organic carbon from wood combustion, Atmos. Chem. Phys., 10, 1773-1787, doi:10.5194/acp-10-1773-2010, 2010.

Dinar, E., Abo Riziq, A., Spindler, C., Erlick, C., Kiss, G., and Rudich, Y.: The complex refractive index of atmospheric and model humic-like substances (HULIS) retrieved by a cavity ring down aerosol spectrometer (CRD-AS), Faraday Discuss., 137, 279-295, 2008.

Eck, T. F., Holben, B. N., Reid, J. S., Dubovik, O., Smirnov, A., O'Neill, N. T., Slutsker, I., and Kinne, S.: Wavelength dependence of the optical depth of biomass burning, urban, and desert dust aerosols, J. Geophys. Res.-Atmos., 104, 3133331349, 1999.

Erlick, C., Haspel, M., and Rudich, Y.: Simultaneous retrieval of the complex refractive indices of the core and shell of coated aerosol particles from extinction measurements using simulated annealing, Appl. Optics, 50, 4393-4402, 2011.

Flores, J. M., Trainic, M., Borrmann, S., and Rudich, Y.: Effective broadband refractive index retrieval by a white light optical particle counter, Phys. Chem. Chem. Phys., 11, 7943-7950, 2009.

Freedman, M. A., Hasenkopf, C. A., Beaver, M. R., and Tolbert, M. A.: Optical Properties of Internally Mixed Aerosol Particles Composed of Dicarboxylic Acids and Ammonium Sulfate, J. Phys. Chem. A, 113, 13584-13592, 2009.

French, R. H., Winey, K. I., Yang, M. K., and Qiu, W. M.: Optical properties and van der Waals-London dispersion interactions of polystyrene determined by vacuum ultraviolet spectroscopy and spectroscopic ellipsometry, Aust. J. Chem., 60, 251-263, 2007.

Galli, M., Guazzotti, S. A., and Prather, K. A.: Improved lower particle size limit for aerosol time-of-flight mass spectrometry, Aerosol Sci. Tech., 34, 381-385, 2001.

Ge, J. M., Su, J., Ackerman, T. P., Fu, Q., Huang, J. P., and Shi, J. S.: Dust aerosol optical properties retrieval and radiative forcing over northwestern China during the 2008 China-US joint field experiment, J. Geophys. Res.-Atmos., 115, D00K12, doi:10.1029/2009JD013263, 2010.

Hecobian, A., Zhang, X., Zheng, M., Frank, N., Edgerton, E. S., and Weber, R. J.: Water-Soluble Organic Aerosol material and the light-absorption characteristics of aqueous extracts measured over the Southeastern United States, Atmos. Chem. Phys., 10, 5965-5977, doi:10.5194/acp-10-5965-2010, 2010.

Hönninger, G., von Friedeburg, C., and Platt, U.: Multi axis differential optical absorption spectroscopy (MAX-DOAS), Atmos. Chem. Phys., 4, 231-254, doi:10.5194/acp-4-231-2004, 2004.

Hoffer, A., Gelencsér, A., Guyon, P., Kiss, G., Schmid, O., Frank, G. P., Artaxo, P., and Andreae, M. O.: Optical properties of humic-like substances (HULIS) in biomass-burning aerosols, Atmos. Chem. Phys., 6, 3563-3570, doi:10.5194/acp-6-3563-2006, 2006.

IPCC: Climate Change 2007: The Physical Science Basis. Contribution of Working Group I to the Fourth Assessment Report of the Intergovernmental Panel on Climate Change, edited by: Solomon, S., Qin, D., Manning, M., Chen, Z., Marquis, M., Averyt, K. B., Tignor, M., and Miller, H. L., Cambridge University Press, Cambridge, UK and New York, US, 27-30, 2007.

Kanakidou, M., Seinfeld, J. H., Pandis, S. N., Barnes, I., Dentener, F. J., Facchini, M. C., Van Dingenen, R., Ervens, B., Nenes, A., Nielsen, C. J., Swietlicki, E., Putaud, J. P., Balkanski, Y., Fuzzi, S., Horth, J., Moortgat, G. K., Winterhalter, R., Myhre, C. E. L., Tsigaridis, K., Vignati, E., Stephanou, E. G., and Wilson, J.: Organic aerosol and global climate modelling: a review, Atmos. Chem. Phys., 5, 1053-1123, doi:10.5194/acp-5-1053-2005, 2005.

Kim, H., Barkey, B., and Paulson, S. E.: Real refractive indices of 
alpha- and beta-pinene and toluene secondary organic aerosols generated from ozonolysis and photo-oxidation, J. Geophys. Res.-Atmos., 115, D24212, doi:10.1029/2010JD014549, 2010.

Kirchstetter, T. W., Novakov, T., and Hobbs, P. V.: Evidence that the spectral dependence of light absorption by aerosols is affected by organic carbon, J. Geophys. Res.-Atmos., 109, D21208, doi:10.1029/2004JD004999, 2004.

Lack, D. A., Lovejoy, E. R., Baynard, T., Pettersson, A., and Ravishankara, A. R.: Aerosol absorption measurement using photoacoustic spectroscopy: Sensitivity, calibration, and uncertainty developments, Aerosol Sci. Tech., 40, 697-708, 2006.

Lang-Yona, M., Rudich, Y., Segre, E., Dinar, E., and Abo-Riziq, A.: Complex Refractive Indices of Aerosols Retrieved by Continuous Wave-Cavity Ring Down Aerosol Spectrometer, Anal. Chem., 81, 1762-1769, 2009.

Lang-Yona, N., Abo-Riziq, A., Erlick, C., Segre, E., Trainic, M., and Rudich, Y.: Interaction of internally mixed aerosols with light, Phys. Chem. Chem. Phys., 12, 21-31, 2010.

Liu, B. Y. H., Romay, F. J., Dick, W. D., Woo, K. S., and Chiruta, M.: A Wide-Range Particle Spectrometer for Aerosol Measurement from $0.010 \mu \mathrm{m}$ to $10 \mu \mathrm{m}$, Aerosol Air Qual. Res., 10, 125 139,2010

Ma, X. Y., Lu, J. Q., Brock, R. S., Jacobs, K. M., Yang, P., and Hu, $X$. H.: Determination of complex refractive index of polystyrene microspheres from 370 to 1610 nm, Phys. Med. Biol., 48, 41654172, 2003.

Mack, L. A., Levin, E. J. T., Kreidenweis, S. M., Obrist, D., Moosmller, H., Lewis, K. A., Arnott, W. P., McMeeking, G. R., Sullivan, A. P., Wold, C. E., Hao, W.-M., Collett Jr., J. L., and Malm, W. C.: Optical closure experiments for biomass smoke aerosols, Atmos. Chem. Phys., 10, 9017-9026, doi:10.5194/acp10-9017-2010, 2010.

Mätzler, C.: MATLAB Functions for Mie Scattering and Absorption - Version 2. Research Report (No. 2002-11), Institut für Angewandte Physik, 2002.

Marley, N. A., Gaffney, J. S., Tackett, M., Sturchio, N. C., Heraty, L., Martinez, N., Hardy, K. D., Marchany-Rivera, A., Guilderson, T., MacMillan, A., and Steelman, K.: The impact of biogenic carbon sources on aerosol absorption in Mexico City, Atmos. Chem. Phys., 9, 1537-1549, doi:10.5194/acp-9-1537-2009, 2009.

Massoli, P., Bates, T. S., Quinn, P. K., Lack, D. A., Baynard, T., Lerner, B. M., Tucker, S. C., Brioude, J., Stohl, A., and Williams, E. J.: Aerosol optical and hygroscopic properties during TexAQS-GoMACCS 2006 and their impact on aerosol direct radiative forcing, J. Geophys. Res.-Atmos., 114, D00F07, doi:10.1029/2008JD011604, 2009.

Massoli, P., Kebabian, P. L., Onasch, T. B., Hills, F. B., and Freedman, A.: Aerosol Light Extinction Measurements by Cavity Attenuated Phase Shift (CAPS) Spectroscopy: Laboratory Validation and Field Deployment of a Compact Aerosol Particle Extinction Monitor, Aerosol Sci. Tech., 44, 428-435, 2010.

Mellon, D., King, S. J., Kim, J., Reid, J. P., and Orr-Ewing, A. J.: Measurements of Extinction by Aerosol Particles in the Near-Infrared Using Continuous Wave Cavity Ring-Down Spectroscopy, J. Phys. Chem. A, 115, 774-783, 2011.

Meyrahn, H., Pauly, J., Schneider, W., and Warneck, P.: Quantum Yields for the Photodissociation of Acetone in Air and an Estimate for the Life Time of Acetone in the Lower Troposphere, J.
Atmos. Chem., 4, 277-291, 1986.

Miles, R. E. H., Rudic, S., Orr-Ewing, A. J., and Reid, J. P.: Influence of Uncertainties in the Diameter and Refractive Index of Calibration Polystyrene Beads on the Retrieval of Aerosol Optical Properties Using Cavity Ring Down Spectroscopy, J. Phys. Chem. A, 114, 7077-7084, 2010a.

Miles, R. E. H., Rudic, S., Orr-Ewing, A. J., and Reid, J. P.: Measurements of the wavelength dependent extinction of aerosols by cavity ring down spectroscopy, Phys. Chem. Chem. Phys., 12, 3914-3920, 2010b.

Moffet, R. C. and Prather, K. A.: In-situ measurements of the mixing state and optical properties of soot with implications for radiative forcing estimates, P. Natl. Acad. Sci. USA, 106, 11872 11877, 2009.

Mogili, P. K., Yang, K. H., Young, M. A., Kleiber, P. D., and Grassian, V. H.: Environmental aerosol chamber studies of extinction spectra of mineral dust aerosol components: Broadband IRUV extinction spectra, J. Geophys. Res.-Atmos., 112, D21204, doi:10.1029/2007JD008890, 2007.

Moosmüller, H., Varma, R., and Arnott, W. P.: Cavity ring-down and cavity-enhanced detection techniques for the measurement of aerosol extinction, Aerosol Sci. Tech., 39, 30-39, 2005.

Moosmüller, H., Chakrabarty, R. K., Ehlers, K. M., and Arnott, W. P.: Absorption Ångström coefficient, brown carbon, and aerosols: basic concepts, bulk matter, and spherical particles, Atmos. Chem. Phys., 11, 1217-1225, doi:10.5194/acp-11-12172011, 2011.

Nikolov, I. D. and Ivanov, C. D.: Optical plastic refractive measurements in the visible and the near-infrared regions, Appl. Optics, 39, 2067-2070, 2000.

Pettersson, A., Lovejoy, E. R., Brock, C. A., Brown, S. S., and Ravishankara, A. R.: Measurement of aerosol optical extinction at $532 \mathrm{~nm}$ with pulsed cavity ring down spectroscopy, J. Aerosol Sci., 35, 995-1011, 2004.

Platt, U. and Stutz, J.: Differential Optical Absorption Spectroscopy: Principles and Applications, Springer, New York,, 597 pp., 2008.

Schnaiter, M., Horvath, H., Mohler, O., Naumann, K. H., Saathoff, H., and Schock, O. W.: UV-VIS-NIR spectral optical properties of soot and soot-containing aerosols, J. Aerosol Sci., 34, 14211444, 2003.

Schnaiter, M., Schmid, O., Petzold, A., Fritzsche, L., Klein, K. F., Andreae, M. O., Helas, G., Thielmann, A., Gimmler, M., Mohler, O., Linke, C., and Schurath, U.: Measurement of wavelengthresolved light absorption by aerosols utilizing a UV-VIS extinction cell, Aerosol Sci. Tech., 39, 249-260, 2005.

Si, F. Q., Xie, P. H., Dou, K., Zhan, K., Liu, Y., Xu, J., and Liu, W. Q.: Determination of the atmospheric aerosol optical density by multi axis differential optical absorption spectroscopy, Acta Phys. Sin.-Ch. Ed., 59, 2867-2872, 2010.

Smith, J. D. and Atkinson, D. B.: A portable pulsed cavity ringdown transmissometer for measurement of the optical extinction of the atmospheric aerosol, Analyst, 126, 1216-1220, 2001.

Spindler, C., Abo Riziq, A., and Rudich, Y.: Retrieval of aerosol complex refractive index by combining cavity ring down aerosol spectrometer measurements with full size distribution information, Aerosol Sci. Tech., 41, 1011-1017, 2007.

Strawa, A. W., Castaneda, R., Owano, T., Baer, D. S., and Paldus, B. A.: The measurement of aerosol optical properties using contin- 
uous wave cavity ring-down techniques, J. Atmos. Ocean. Tech., 20, 454-465, 2003.

Strawa, A. W., Elleman, R., Hallar, A. G., Covert, D., Ricci, K., Provencal, R., Owano, T. W., Jonsson, H. H., Schmid, B., Luu, A. P., Bokarius, K., and Andrews, E.: Comparison of in situ aerosol extinction and scattering coefficient measurements made during the Aerosol Intensive Operating Period, J. Geophys. Res., 111, D05S03, doi:10.1029/2005JD006056, 2006.

Takashima, H., Irie, H., Kanaya, Y., Shimizu, A., Aoki, K., and Akimoto, H.: Atmospheric aerosol variations at Okinawa Island in Japan observed by MAX-DOAS using a new cloudscreening method, J. Geophys. Res.-Atmos., 114, D18213, doi:10.1029/2009JD011939, 2009.

Thermo Fisher Scientific: available at: http://www.thermo. fr/eThermo/CMA/PDFs/Various/File_3936.pdf (last access: 29 September 2011), 2009.

Thermo Fisher Scientific: available at: http://www.thermoscien tific.com/ecomm/servlet/productsdetail?navigationId=L10397 \& categoryId=87439 $\backslash \&$ productId=11962886\&\&store $I d=11152$, last access: 4 January 2012.
Virkkula, A., Ahlquist, N. C., Covert, D. S., Sheridan, P. J., Arnott, W. P., and Ogren, J. A.: A three-wavelength optical extinction cell for measuring aerosol light extinction and its application to determining light absorption coefficient, Aerosol Sci. Tech., 39, 52-67, 2005.

Voigt, S., Orphal, J., Bogumil, K., and Burrows, J. P.: The temperature dependence (203-293 K) of the absorption cross sections of $\mathrm{O}_{3}$ in the 230-850 $\mathrm{nm}$ region measured by Fourier-transform spectroscopy, J. Photoch. Photobio. A, 143, 1-9, 2001.

White, J. U.: Long optical paths of large aperture, J. Opt. Soc. Am., 32, 285-288, 1942.

Yang, M., Howell, S. G., Zhuang, J., and Huebert, B. J.: Attribution of aerosol light absorption to black carbon, brown carbon, and dust in China - interpretations of atmospheric measurements during EAST-AIRE, Atmos. Chem. Phys., 9, 2035-2050, doi:10.5194/acp-9-2035-2009, 2009. 